\title{
The Sequential Appearance of Low- and High-Molecular-Weight Forms of MAP2 in the Developing Cerebellum
}

\author{
R. P. Tucker, ${ }^{1}$ L. I. Binder, ${ }^{2}$ C. Viereck, ${ }^{1}$ B. A. Hemmings, ${ }^{1}$ and A. I. Matus' \\ 'Friedrich Miescher Institute, $\mathrm{CH}-4002$ Basel, Switzerland, and 'Department of Cell Biology and Anatomy, School of \\ Medicine and Dentistry, University of Alabama at Birmingham, Birmingham, Alabama 35294
}

Mammalian microtubule-associated protein 2 (MAP2) exists in high-molecular-weight $\left(M_{r} \sim 280,000\right)$ and low-molecularweight $\left(M_{r} \sim 70,000\right)$ forms, with the latter protein being more abundant in embryonic brain homogenates than in preparations from mature brain (Riederer and Matus, 1985). In the current study, we have shown that avian MAP2 also exists as both high- $\left(M_{r} \sim 260,000\right)$ and low-molecular-weight $\left(M_{r}\right.$ $\sim 65,000$ ) forms whose relative abundance changes during brain maturation, indicating a conserved function for these proteins during vertebrate neuronal morphogenesis. Using indirect immunohistochemistry, we have determined the cellular distribution of the high- and low-molecular-weight forms of MAP2 in the developing avian cerebellum. In the embryonic cerebellum, low-molecular-weight MAP2 is found in the external granular layer and in epithelial cells. High-molecular-weight MAP2 is found only in neurons that have commenced dendrogenesis, i.e., Purkinje cells and neurons within the internal granular layer. Thus, low-molecular-weight MAP2 is not only more abundant in embryonic nervous tissue than in the adult, but it also appears in glia and in differentiating neurons before the high-molecular-weight form. We have also shown that in the mature cerebellum high-molecular-weight MAP2 cannot be detected with monoclonal antibodies or polyclonal antisera in Purkinje cell dendrites. Polyclonal antisera against the regulatory subunit of the CAMP-dependent protein kinase, which is associated with MAF2 in the Purkinje cell dendrites of the rat, also fail to stain Purkinje cell dendrites in the mature quail cerebellum. This suggests that high-molecular-weight MAP2 may be necessary for the establishment of dendrites but is not necessary for the maintenance of dendritic form.

Microtubule-associated proteins (MAPs) have been implicated as key regulators of the morphogenesis, function, and maintenance of the nervous system. For example, brain MAPs have been shown to be developmentally regulated, with their molecular form and abundance undergoing substantial changes during development (Nunez, 1986; Matus, 1988). Moreover, immunohistochemical studies with monoclonal antibodies have shown that many MAPs are compartmentalized within neurons, being enriched in either axons or dendrites, and in vitro studies have

Received Oct. 26, 1987; revised Apr. 1, 1988; accepted Apr. 4, 1988.

This work was supported in part by U.S. Public Health Service Grant AG06969 to L.I.B. We wish to thank W. Halfter, G. Huber, and E. Mackie for constructive criticism of the manuscript.

Correspondence should be addressed to Richard P. Tucker, Friedrich Miescher Institute, P.O. Box 2543, CH-4002 Basel, Switzerland.

Copyright $(C) 1988$ Society for Neuroscience $0270-6474 / 88 / 124503-10 \$ 02.00 / 0$ shown that a number of MAPs promote the assembly of tubulin into microtubules and stabilize the resulting microtubules against the depolymerizing effects of cold and various pharmacological agents (Olmsted, 1986; Matus, 1988). The most abundant MAP in the mammalian CNS, MAP2, displays each of these characteristics: (1) There are 2 closely related high-molecular-weight (HMW) forms of MAP2, MAP2a, and MAP2b, which change in relative abundance during development (Binder et al., 1984; Burgoyne and Cummings, 1984); (2) MAP2 is found in dendrites and only rarely in axons (e.g., Caceres et al., 1984; DeCamilli et al., 1984; Huber and Matus, 1984b); and (3) MAP2 stabilizes and promotes the assembly of microtubules in vitro (Murphy and Borisy, 1975; Sloboda et al., 1976; Herzog and Weber, 1978).

Recently, a low-molecular-weight (LMW) form of MAP2, MAP2c, has been described in the rat (Riederer and Matus, 1985; Garner et al., 1988). Initially shown to be related to HMW MAP2 by a common monoclonal antibody epitope, the LMW form of MAP2 is probably encoded by the same gene as HMW MAP2 (Garner and Matus, 1988). In contrast to MAP2a, MAP2c is plentiful in embryonic and neonatal rat brain homogenates, and decreases dramatically in abundance during the second week of postnatal development.

Using MAP2 monoclonal antibodies and polyclonal antisera, we have studied the distribution and developmental regulation of HMW and LMW MAP2 forms during the morphogenesis of the avian cerebellum. By using an avian model system, we have been able to determine which aspects of the intracellular compartmentalization and changes in MAP2 form are conserved, implying a fundamental function, in 2 classes of vertebrates. Furthermore, by comparing the onset of expression and localization of the HMW and LMW forms of MAP2 in differentiating tissue, it is now possible to envisage the function of MAP2 during neuronal morphogenesis more clearly.

\section{Materials and Methods}

Experimental animals. Quail (Coturnix coturnix) eggs were kept at $37^{\circ} \mathrm{C}$ in a humidified incubator until embryonic day 10 (E10), E12, or E14 (a day before hatching). Juvenile quait ( $9 \mathrm{~d}$ after hatching, P9) were used as a source of mature (no or greatly reduced external granular layer) cerebellums.

Monoclonal antibodies and polyclonal antisera. The production and characterization of several of the monoclonal antibodies to microtubule proteins used in this study have been described in detail elsewhere (AP14: Binder et al., 1986; MAb/C: Huber and Matus, 1984b; Tu27b: Binder et al., 1986). Monoclonal antibody AP14 recognizes only the HMW forms of MAP2 on Western blots of mammalian brain microtubule protein (Binder et al., 1986), whereas monoclonal antibody C (MAb/C) recognizes both of the HMW forms of MAP2, as well as LMW MAP2 (Riederer and Matus, 1985). Tu27b is specific for $\beta$-tubulin. The 

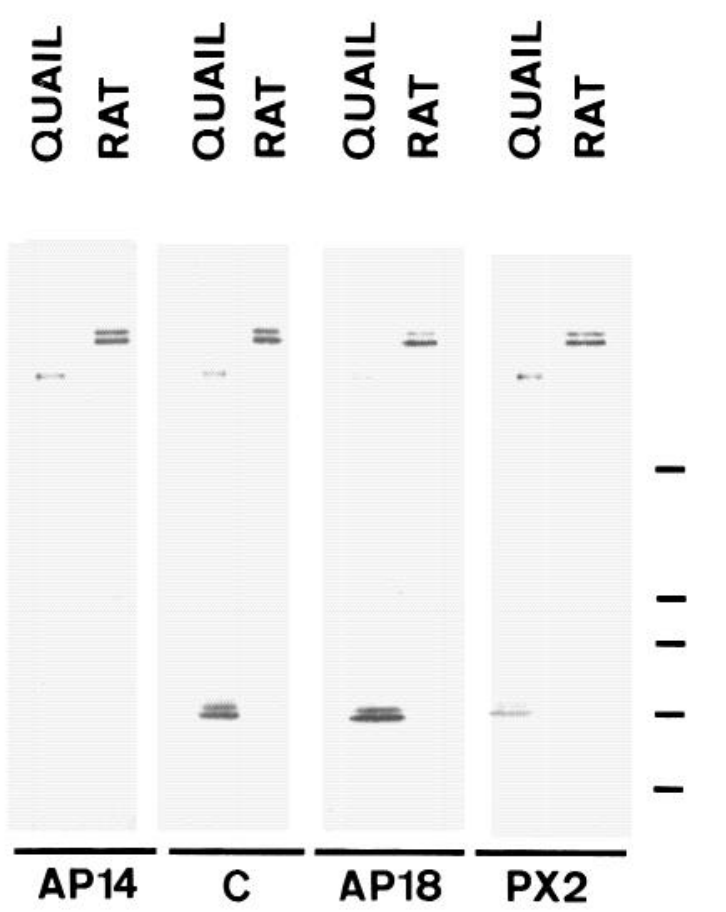

Figure 1. Immunoblots of $\mathrm{P} 9$ quail and adult rat brain microtubule proteins stained with monoclonal antibodies and polyclonal antisera to MAP2. Molecular weights are indicated by dashes at the far right (from top to bottom: $M_{r} 200,000,116,000,95,000,66,000$, and 45,000). Monoclonal antibody AP14 stains the HMW MAP2 doublet (MAP2a and MAP2b) in the rat preparation and a single band with an apparent molecular weight of $\sim 260,000$ on quail microtubule immunoblots. Monoclonal antibodies C and AP18, as well as polyclonal antisera PX2, stain the same HMW MAP2 bands as AP14, as well as a LMW (M, $\sim 65,000$ ) doublet on the quail immunoblot. LMW MAP2 can be detected immunohistochemically by staining adjacent sections with AP14 and an antibody that recognizes both HMW and LMW MAP2 (e.g., C); the differences between the staining patterns will represent the LMW form of MAP2.

specificity of MAP2 monoclonal antibody AP18, which was raised according to the methods described in Binder et al. (1986), was determined by Western blotting (see below). Polyclonal antisera against MAP2 (PX2) was raised using a HMW MAP from adult Xenopus laevis brain as an antigen. In brief, a HMW band with an apparent molecular weight corresponding to mammalian MAP2 was cut from an SDS-polyacrylamide gel, homogenized in PBS with Freund's complete adjuvant, and injected into the peritoneum of a Balb/c mouse. After 3 immunizations with the antigen mixed in Freund's incomplete adjuvant, the serum was collected and screened by immunoblotting (see below). The affinitypurified rabbit antisera to bovine heart $R_{11}$ has been described elsewhere (Hemmings et al., 1986).

Protein preparations and immunoblotting. Adult rat brain and $\mathrm{P} 9$ quail brain cold-warm cycled microtubules were made essentially as described by Karr et al. (1979). Brain supernatant proteins were made from E10, E14, and P9 quail by centrifuging brain homogenates at $90,000 \times g$ for $45 \mathrm{~min}$ at $4^{\circ} \mathrm{C}$ in MES buffer $(0.1 \mathrm{M}$ morpholinoethanesulfonic acid, $1 \mathrm{~mm}$ EGTA, $0.5 \mathrm{~mm} \mathrm{MgCl}_{2}$; $\mathrm{pH}$ 6.6). Protein concentrations were determined by the BioRad microassay procedure. In order to determine if the different bands composing LMW-MAP2 in the quail were the result of phosphorylation, approximately $30 \mu \mathrm{g}$ of supernatant proteins were treated overnight with $5 \mathrm{U}$ of calf intestinal alkaline phosphatase (CIP; Boehringer Mannheim) in Tris buffer $(0.1$ м Tris, 1 mM EGTA; $\mathrm{pH} 8.0$ ) at $37^{\circ} \mathrm{C}$ or in Tris buffer alone under the same conditions. Approximately equal amounts of quail and rat brain microtubule proteins $(4 \mu \mathrm{g} / 3 \mathrm{~mm}$ lane) or brain supernatant proteins from the different developmental ages $(1.5 \mu \mathrm{g} / 3 \mathrm{~mm})$ were separated on a $3-15 \%$ gradient SDS-polyacrylamide gel (Laemmli, 1970) and transferred electrophoretically to nitrocellulose filters (Towbin et al., 1979). Transferred molecular-weight standards were stained with Ponceau red.
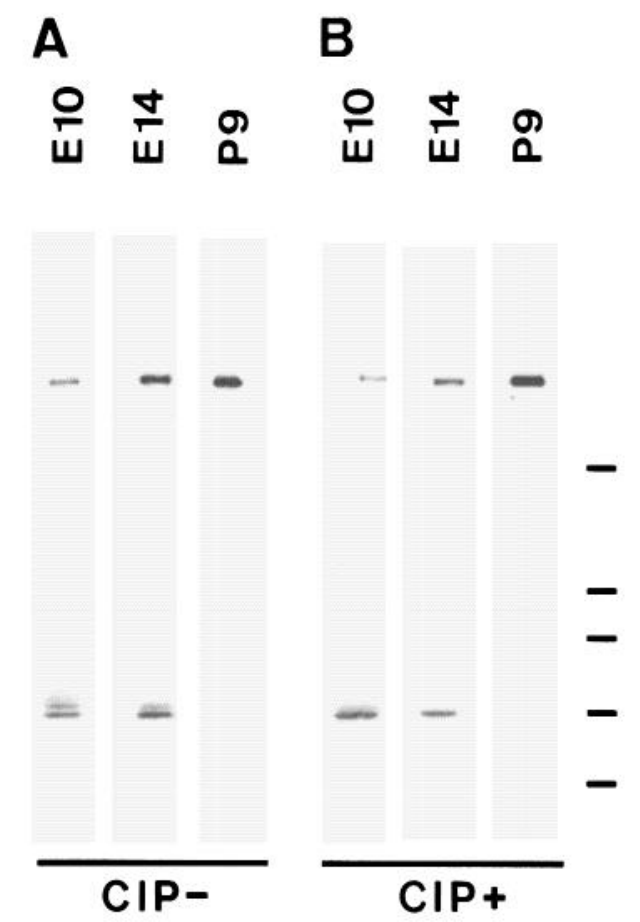

Figure 2. Immunoblots of embryonic and mature quail brain supernatant proteins stained with monoclonal antibody C. Molecular weights are indicated by dashes at the far right (from top to bottom: $M_{r} 200,000$, $116,000,95,000,66,000$, and 45,000$)$. The relative abundance of the LMW form of MAP2 decreases as the brain matures $(A)$. When the same proteins are incubated with calf intestinal alkaline phosphatase (CIP), the multiple LMW MAP2 bands resolve into a single $M_{r} 65,000$ band $(B)$, indicating that the heterogeneity of LMW MAP2 forms is due to phosphorylation.

Nitrocellulose filters with transferred brain proteins were blocked with $5 \%$ skim milk in PBS, incubated in the MAP2 monoclonal antibodies (diluted hybridoma supernatants, 1:20 in PBS) or polyclonal antisera (diluted 1:400 in PBS) for $2 \mathrm{hr}$, rinsed in PBS, and incubated for $1 \mathrm{hr}$ with HRP-conjugated rabbit anti-mouse IgG (1:500 in PBS; Dakopatts). The antibodies were visualized using chloronaphthol as chromogen.

Immunohistochemistry. Whole embryonic quail heads or freshly dissected P9 cerebellums were fixed by immersion in cold $4 \%$ paraformaldehyde in potassium phosphate buffer $(0.1 \mathrm{M}, \mathrm{pH} 7.5)$ for $4 \mathrm{hr}$. The tissue was then rinsed in PBS $(0.1 \mathrm{M}, \mathrm{pH} 7.5)$ and cryoprotected in $25 \%$ sucrose/PBS overnight. Heads or cerebellums were embedded in O.C.T. compound (Miles), frozen, and sectioned sagittally at $20 \mu \mathrm{m}$ in a Reichert-Jung model 2700 cryostat. Serial sections were collected on gelatin-coated slides, air-dried for $2-3 \mathrm{hr}$, rinsed in PBS, blocked in $0.5 \%$ $\mathrm{BSA}$, and incubated overnight with monoclonal antibodies (hybridoma supernatants) or polyclonal antisera diluted in $0.5 \% \mathrm{BSA} / \mathrm{PBS}$. Control sections were treated identically except for incubation in $0.5 \%$ BSA PBS without antibodies. Since MAP epitopes can be masked in situ by phosphorylation (Papasozomenos and Binder, 1987), some sections were treated with CIP before incubation with the MAP2 monoclonal antibodies (Sternberger and Sternberger, 1983; Tucker et al., 1988a). After monoclonal antibody incubation, sections were rinsed in PBS and incubated for $2 \mathrm{hr}$ in rhodamine-conjugated rabbit anti-mouse IgG (Dakopatts) or fluorescein-conjugated goat anti-rabbit IgG (Dakopatts). Sections were rinsed in PBS, counterstained with Hoechst nuclear dye (bisbenzimidine H 33258, Riedel-de Haën), and coverslipped in 50\% glycerol with $1 \%$ azide.

\section{Results}

Quail have both $H M W$ and $L M W$ forms of $M A P 2$

The specificity of each of the MAP2 monoclonal antibodies and the polyclonal antisera used for immunohistochemistry was tested by immunoblotting (Fig. 1). AP14 recognizes the HMW 

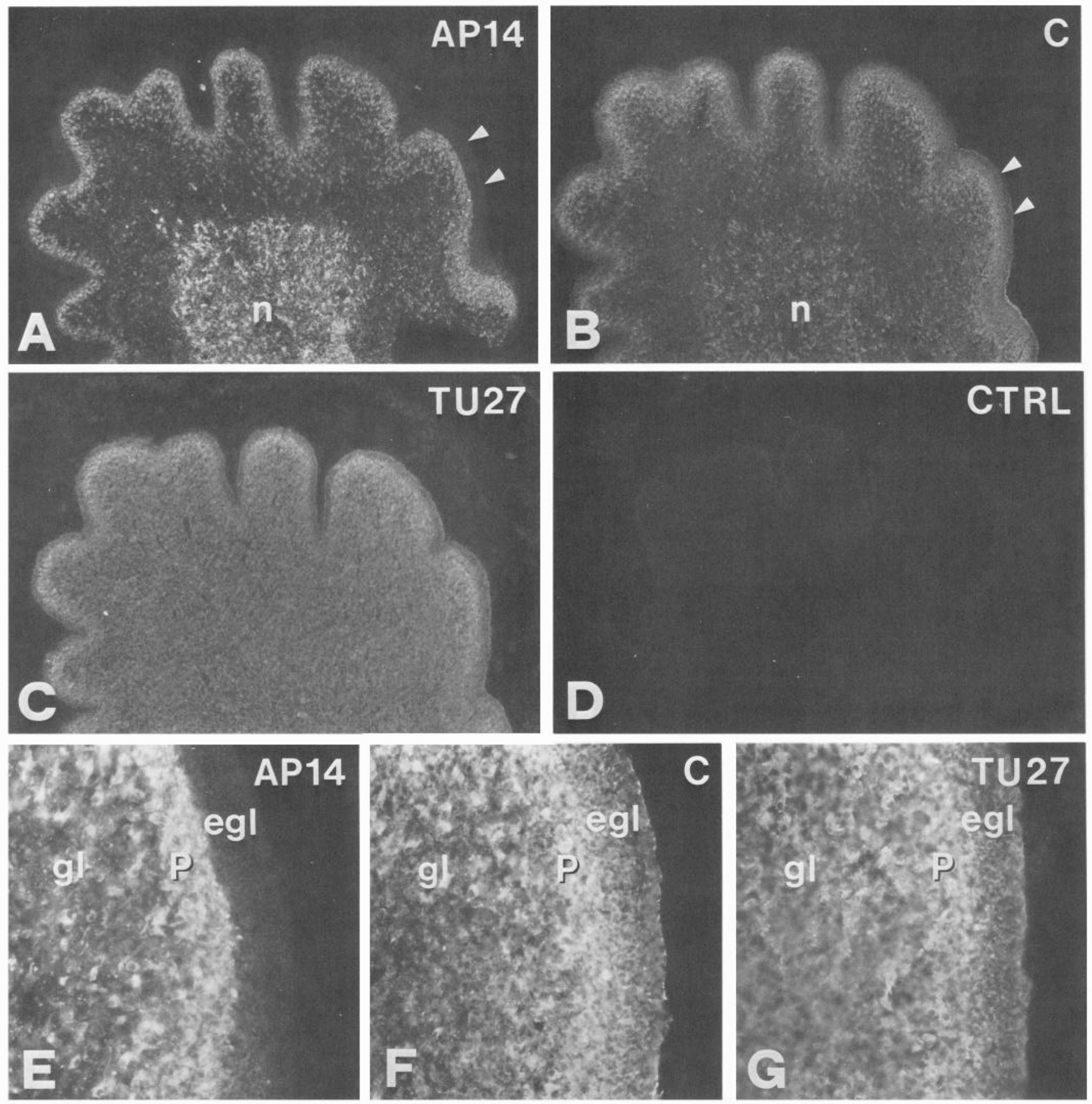

Figure 3. Immunohistochemical staining of adjacent sections of the E10 quail cerebellum photographed at low $(A-D)$ and high $(E-G)$ magnification. Monoclonal antibody AP14 $(A, E)$ reveals HMW MAP2 in the deep cerebellar nuclei $(n)$, Purkinje cells $(P)$, and cells scattered in the granular layer $(g l)$. The external granular layer $(e g l$, arrowheads) is unstained. Low $(B)$ and high $(F)$ magnification of an adjacent section stained with monoclonal antibody $\mathrm{C}$ reveals a pattern similar to the AP14 staining pattern, except for staining in the external granular layer (arrows). The $\beta$-tubulin monoclonal antibody Tu27 $(D, G)$ stains Purkinje cells intensely and the remainder of the E10 cerebellum relatively uniformly. Sections incubated with secondary antibody alone are unstained $(D)$.

MAP2 doublet $\left(\mathrm{M}_{\mathrm{r}} \sim 280,000\right)$ on blots of adult rat brain microtubules and a single HMW band $\left(\mathrm{M}_{\mathrm{r}} \sim 260,000\right)$ on blots of quail brain microtubules. An identical staining pattern is observed on immunoblots stained with monoclonal antibodies $\mathrm{C}$ and AP18, as well as polyclonal antisera PX2. The latter 3 antibodies and antisera also stain a doublet with an electrophoretic mobility similar $\left(\mathrm{M}_{\mathrm{r}} \sim 65,000\right)$ to rat MAP2c. Thus, the quail, like the rat, has a LMW form of MAP2, and its distri- bution can be determined by staining adjacent sections with monoclonal antibodies AP14 and C.

\section{$L M W M A P 2$ is developmentally regulated in quail}

In order to ascertain changes in the patterns of expression of MAP2 during quail brain development, brain supernatant proteins from the 3 developmental stages used for immunohistochemical analysis were immunoblotted and stained with mono- 
clonal antibody $\mathrm{C}$ (Fig. 2A). At E10 and E14, LMW MAP2 is relatively abundant in brain supernatants, but $9 \mathrm{~d}$ after hatching, LMW MAP2 is no longer detectable by immunoblotting. LMW MAP2 is still present at P9, as can be seen when it is enriched in the microtubule fraction blotted in Figure 1. Thus, LMW MAP2 is developmentally regulated in the quail as it is in the rat (Riederer and Matus, 1985). It is abundant in the embryo but is relativcly scarce compared with HMW MAP2 in more mature brain.

LMW MAP2 in the embryonic quail brain resolves as 2-4 bands. Since HMW MAP2 can be phosphorylated (Sloboda et al., 1976), we were interested in determining if the apparent heterogeneity of LMW MAP2 in the quail was the result of different levels of phosphorylation. After treatment in CIP, LMW MAP2 resolves into a faint doublet or a single band with an apparent molecular weight of 65,000 (Fig. $2 B$ ), indicating that the complexity of LMW MAP2 is probably the result of different levels of protein phosphorylation.

\section{$M A P 2$ forms in the developing cerebellum}

In the E10 cerebellum, the HMW-specific MAP2 monoclonal antibody AP14 stains the Purkinje cell layer intensely, as well as the deep cerebellar nuclei and cells scattered throughout the granular layer (Fig. 34). The external granular layer is completely unstained by AP14 (Fig. $3 E$ ). In contrast, $\mathrm{MAb} / \mathrm{C}$ stains the external granular layer, as well as scattered cells in the granular layer, the Purkinje cell layer, and cells of the deep cerebellar nuclei (Fig. 3, $B, F$ ). The inner portion of the external granular layer is stained more intensely than the outer portion. The staining with $\mathrm{MAb} / \mathrm{C}$ resembles the staining seen with the $\beta$-tubulin monoclonal antibody ( $\mathrm{Tu} 27 \mathrm{~b}$ ), except that the latter monoclonal antibody does not stain the cells of the deep nuclei as intensely as $\mathrm{MAb} / \mathrm{C}$ (Fig. 3, $C, G$ ). Control sections are completely unstained (Fig. $3 D$ ).

In the E14 cerebellum, the AP14 staining pattern is essentially unchanged from the pattern at E10: the external granular layer and developing molecular layer and white matter are completely unstained, whereas the Purkinje cells and cells within the granular layer are stained intensely (Fig. $4, A, E$ ). Cells within the deep cerebellar nuclei are also stained. $\mathrm{MAb} / \mathrm{C}$ stains the external granular layer, as well as the cells stained by AP14 (Fig. $4, B, F)$. MAb/C also stains the Bergmann fibers of the developing Golgi epithelial cells intensely. The $\mathrm{MAb} / \mathrm{C}$ pattern resembles the anti- $\beta$-tubulin (Tu27b) staining pattern (Fig. 4, $C$, $G)$, except that the latter antibody stains the developing molecular layer intensely. This staining probably represents parallel fibers. The staining patterns with both of thc MAP2 monoclonal antibodies were not changed when the sections were first treated with CIP under conditions known to remove phosphate groups from MAPs (results not shown).

Thus, in the embryonic avian cerebellum, LMW MAP2, which is stained by MAb/C but not AP14 (Fig. 1), is found in the external granular layer and Bergmann fibers, whereas the HMW form of MAP2 is limited to Purkinje cells, cells of the granular layer, and cells of the deep cerebellar nuclei.

\section{MAP2 forms in the mature cerebellum}

The HMW MAP2-specific monoclonal antibody (AP14) stains cells of the granular layer intensely at P9 (Figs. 5A, 6A). Within the molecular layer, stellate cells as well as vertically coursing beaded processes are stained. Parallel fibers and the white matter are unstained. Interestingly, Purkinje cells, which are stained intensely by AP14 in the embryonic cerebellum, are not stained by AP14 in the mature cerebellum. The HMW and LMW MAP2 monoclonal antibody (MAb/C), like AP14, stains stellate cells and beaded processes in the molecular layer, as well as the granular layer (Figs. $5 B, 6 B$ ). Additionally, there is staining adjacent to the pia in the molecular layer, as well as in smooth, vertical processes in the molecular layer. The former staining most likely is found in the terminal expansions of Golgi epithelial cells and possibly the remnants of the external granular layer, whereas the smooth processes are Bergmann fibers. The white matter is unstained by $\mathrm{MAb} / \mathrm{C}$, except for scattered interneurons. As in the E10 and E14 cerebellum, the staining patterns with both AP14 and C monoclonal antibodies were similar in sections treated with CIP and untreated sections (Fig. $6, C, D)$. In contrast to the staining patterns seen with the MAP2 monoclonal antibodies, the $\beta$-tubulin monoclonal antibody (Tu27b) stains the molecular layer more intensely than the granular layer (Fig. 5C). The white matter, Purkinje cells and their dendrites, and the terminal expansions and Bergmann fibers of epithelial cells are also stained.

\section{MAP2 cannot be detected in mature Purkinje cell dendrites}

Since MAP2 could not be detected with either AP14 or MAb/ $\mathrm{C}$ in Purkinje cells in the P9 cerebellum, even following alkaline phosphatase treatment, we were interested in determining if this could be due to some other form of epitope masking or the limited cross-reactivity of antibodies raised against mammalian MAP2 in quail tissue. We therefore stained adjacent sections of P9 quail cerebellum with $\mathrm{AP} 14$ and $\mathrm{MAb} / \mathrm{C}$, as well as a third MAP2 monoclonal antibody to MAP2, AP18, and a polyclonal antiserum raiscd against a protein from amphibian brain that resembled mammalian MAP2 on SDS-PAGE (PX2). MAP2 cannot be detected in P9 quail Purkinje cells by any of the 3 monoclonal antibodies, nor the polyclonal antisera (Fig. 7A-D). The staining patterns with the 2 monoclonal antibodies that stain both HMW and LMW MAP2 (C and AP18) and PX2 were indistinguishable: Each stained the molecular layer faintly as well as the outer rim of the cerebellar cortex (i.e., the endfeet of Bergmann fibers and the remnants of the external granular layer); all of the antibodies and the antisera stained stellate cells and cells within the granular layer intensely.

P9 quail cerebellums were also stained with polyclonal antisera against the regulatory subunit of the type II cAMP-dependent protein kinase, $R_{1 I}$. The $R_{I I}$ subunit is known to bind to MAP2 from the mammalian brain (Vallee et al., 1981; Theurkauf and Vallee, 1982; Lohmann et al., 1984), and immunohistochemical studies have shown that it is frequently codistributed with MAP2 in mammalian brain (DeCamilli et al., 1986). Our $\mathrm{R}_{\mathrm{II}}$ antibody stains Purkinje cell dendrites and the primary dendrites of pyramidal cells in the rat cerebral cortex, processes that are also stained with our antibodies to MAP2 (results not shown). In contrast, in the quail, $\mathrm{R}_{\mathrm{II}}$ is not found in Purkinje cells or their dendrites in the P9 cerebellum: anti- $\mathrm{R}_{\mathrm{II}}$ staining is limited to thin processes surrounding the Purkinje cell body, the interior portion of the molecular layer, and in the granular layer and white matter (Fig. $4 D$ ). This staining pattern corresponds to the distribution of climbing fibers, which enter the cerebellar cortex from the white matter, and are intimately associated with Purkinje cell bodies and dendrites. Thus, a protein that is known to be associated with MAP2 in mammalian Purkinje cells is absent from these processes in the quail, where there is also no detectable MAP2. 

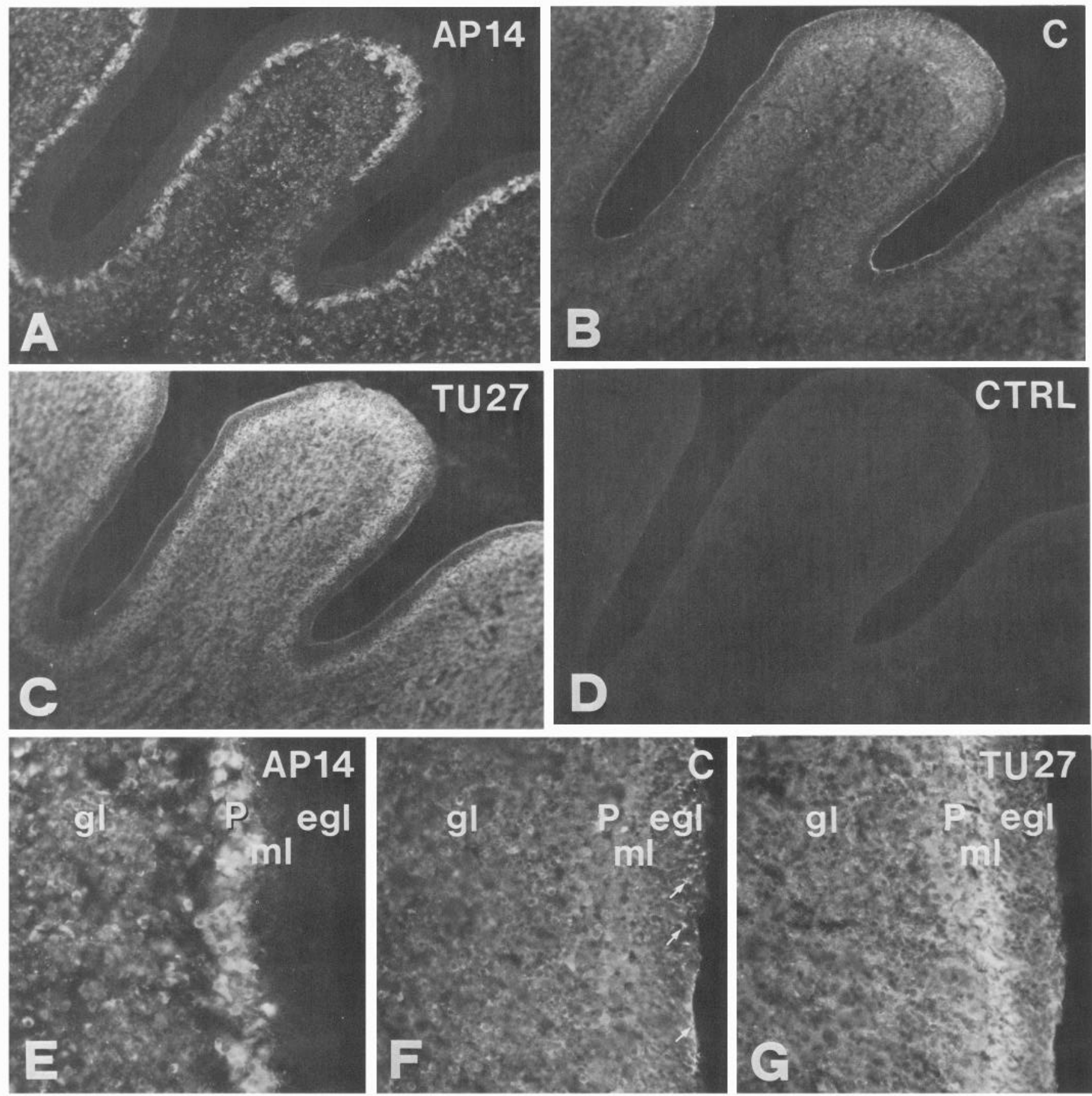

Figure 4. Immunohistochemical staining of adjacent sections of the E14 quail cerebellum photographed at low $(A-D)$ and high $(E-G)$ magnification. Monoclonal antibody AP14 $(A, E)$ stains Purkinje cells $(P)$ and cells within the granular layer $(g l)$. The molecular layer $(m l)$ and external granular layer $(e g l)$ are completely unstained. In contrast, monoclonal antibody c $(B, F)$ stains the external granular layer $(e g l)$ and Bergmann fibers, which appear as points in these slightly oblique sections of the external granular layer (arrows). The staining pattern with anti- $\beta$-tubulin $(C, G)$ resembles the monoclonal antibody $\mathrm{C}$ staining pattern, except that the molecular layer $(\mathrm{ml})$ is stained intensely. Control sections $(D)$ are completely unstained.

\section{Discussion}

MAP2 is developmentally regulated in the quail

In the rat, the abundance of a LMW $\left(M_{r} 70,000\right)$ form of MAP2, MAP2c, is developmentally regulated (Riederer and Matus, 1985). A homologous protein exists in the quail: $\mathrm{A} \mathrm{M}_{\mathrm{r}} 65,000$ protein is recognized in embryonic quail brain homogenates by the same monoclonal antibody $(\mathrm{MAb} / \mathrm{C})$ that was used to identify MAP2 $c$ in the rat, and the abundance of this protein relative to the HMW form of MAP2 decreases dramatically soon after hatching. The conserved antigenicity, form, and regulation of LMW MAP2 in 2 classes of vertebrates suggests a fundamental role for this protein in development of the nervous system.

\section{LMW MAP2 appears before HMW MAP2 in the developing cerebellum}

Peptide mapping and molecular cloning have revealed that LMW MAP2 is apparently identical or very similar to a portion of 

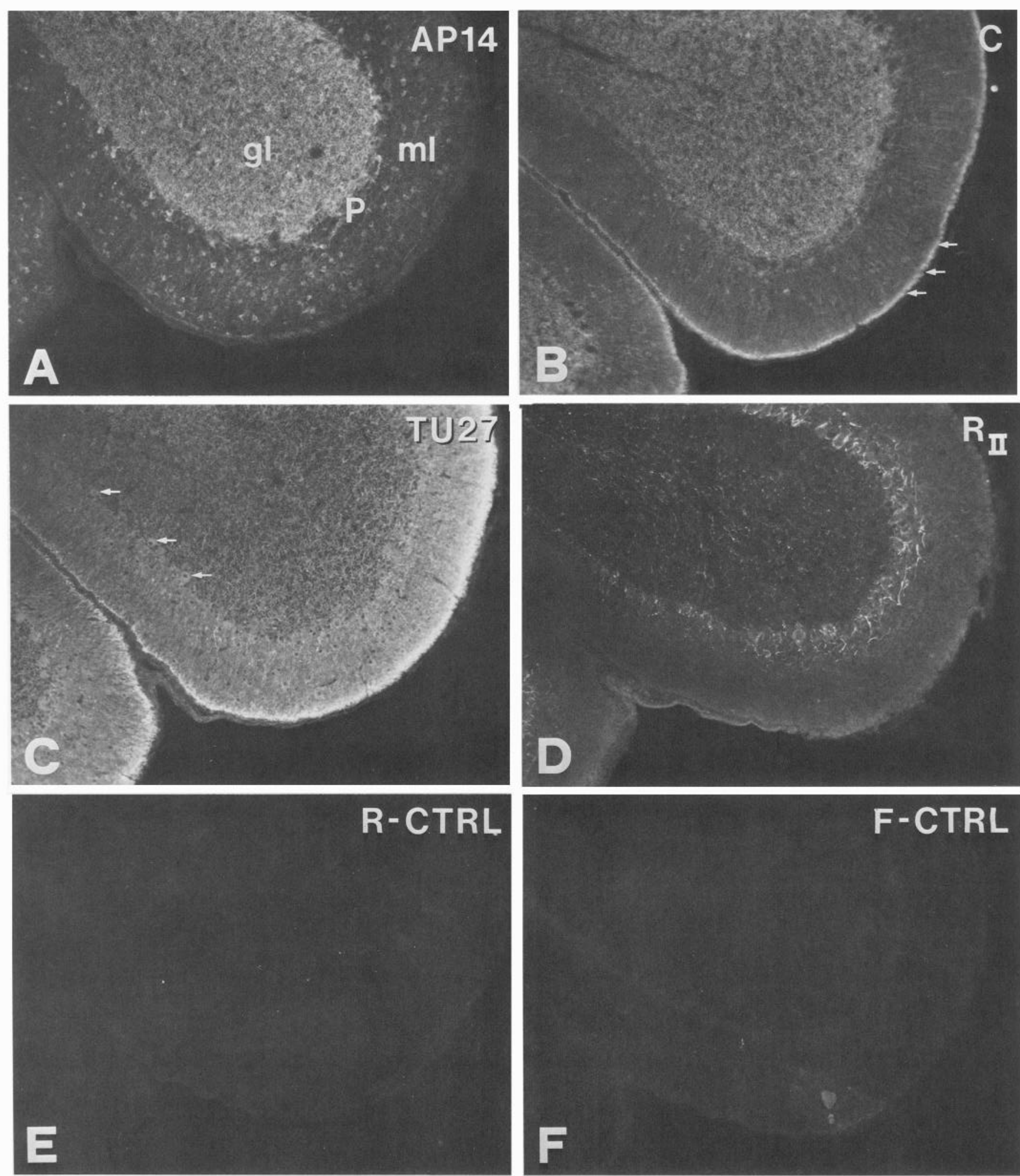

Figure 5. Immunohistochemical staining of adjacent sections of the P9 quail cerebellum. $A$, Monoclonal antibody AP14 stains the granular layer $(\mathrm{gl})$ intensely, as well as scattered cells and processes in the molecular layer $(\mathrm{ml})$. Purkinje cells $(P)$ are completely unstained (see Figs. 6 and 7$)$. $B$, Monoclonal antibody C stains the same cells as AP14, as well as Bergmann fibers and their terminal expansions adjacent to the pia (arrows). This area also contains a 1-cell-thick external granular layer. $C$, Anti- $\beta$-tubulin (Tu27) stains parallel fibers in the molecular layer, as well as Purkinje cell bodies and their dendrites (arrows). $D, \mathrm{R}_{\mathrm{II}}$ is associated with MAP2 in the Purkinje cells of the rat (not shown), but in the quail, anti- $\mathrm{R}_{\mathrm{II}}$ stains processes corresponding to climbing fibers. Purkinje cells and their dendrites are not stained by anti-R $\mathrm{R}_{\mathrm{II}}$. $E$, Control section treated with a TRITCconjugated second antibody (control for Figs. $4 A-C$ ). $F$, Control section treated with a FITC-conjugated second antibody (control for Fig. 4D). 

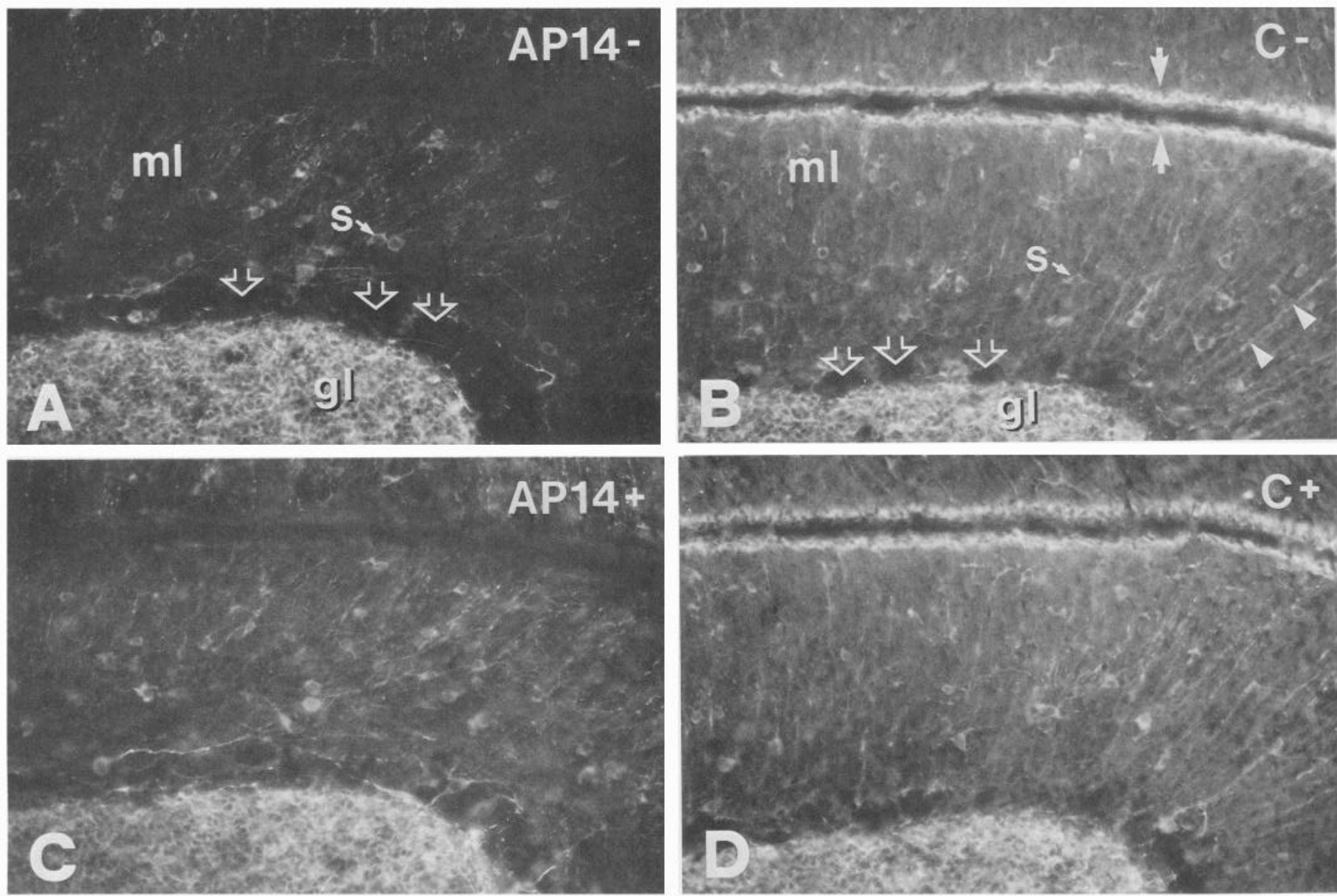

Figure 6. Immunohistochemical staining of the P9 quail cerebellar cortex with monoclonal antibodies to MAP2 with and without calf intestinal alkaline phosphatase (CIP) treatment. $A$, In sections untreated by CIP, AP14 stains beaded processes in the molecular layer $(m l)$, as well as the cell bodies and dendrites of basket cells and stellate cells $(s)$. Purkinje cells are completely unstained (open arrows). Granule cells are stained intensely $(g l)$. B. In untreated sections, monoclonal antibody C stains the same cells as AP14, as well as the remnants of the external granular layer and the terminal expansions of Golgi epithelial cells (arrows) and the Bergmann fibers of these cells (arrowheads). Purkinje cells (open arrows) are completely unstained. $C$ and $D$, Following CIP, the AP14 and monoclonal antibody C staining patterns are unchanged, indicating that the absence of MAP2 staining in Purkinje cells is not due to epitope masking by phosphorylation.

HMW MAP2 (Garner and Matus, 1988; Garner et al., 1988). This is supported by the fact that none of the antibodies tested so far by us have recognized only LMW MAP2; all stain either the HMW form alone or both HMW and LMW forms. Without a LMW MAP2-specific antibody, we have determined the histological distribution of LMW MAP2 by subtracting the staining pattern of a HMW-specific monoclonal antibody (AP14) from the staining pattern of a monoclonal antibody that recognizes both HMW and LMW forms (MAb/C). In this way, we are able to deduce the distribution of LMW MAP2 in regions where it is not codistributed with the HMW MAP2. There are a number of arguments that support the validity of this method: (1) AP14 consistently recognizes a subset of the $\mathrm{MAb} / \mathrm{C}$ staining pattern, as would be expected if the latter antibody stained the same protein as the former, as well as a second protein; (2) the differences between the 2 staining patterns are the most dramatic in the embryo, when LMW MAP2 is readily detectable on immunoblots of brain protein; (3) treatment of sections with alkaline phosphatase (under conditions known to strip phosphate groups from MAPs) does not affect the AP14 staining pattern, indicating that the more restricted staining seen with AP14 is not simply the result of epitope masking in some cells by phosphorylation (see also Tucker et al., 1988a); and (4) we have also stained P9 quail cerebellum sections with a third monoclonal antibody to MAP2 (AP18) and a polyclonal antiserum that recognizes LMW MAP2, and these stain the same structures that are stained by $\mathrm{MAb} / \mathrm{C}$. We have recently used the "subtraction method" for localizing LMW MAP2 in the developing retina (Tucker et al., 1988a), spinal cord, and primary cultures of sensory neurons (Tucker et al., 1988b).

On immunoblots of brain proteins from both the rat and quail, both HMW and LMW forms of MAP2 are present at the earliest stages examined. Here, we report immunohistochemical evidence that LMW MAP2 is not simply more abundant in embryonic neurons, but exists in neurons before HMW MAP2 appears. Our findings are summarized schematically in Figure 8. In the E10 and E14 quail cerebellum, LMW MAP2 is found in the external granular layer, which is composed of the mitotic and postmitotic progenitors of granule cells and stellate cells. In contrast, HMW MAP2 is found in more mature neurons: cells of the deep cerebellar nuclei and Purkinje cells, which are stained by AP14 at E10, are among the first neurons in the cerebellum to differentiate (Ramón y Cajal, 1929). HMW MAP2staining is intense in the granule cells only after these cells have reached their mature configuration in the granular layer. Therefore, LMW MAP2 is not only more abundant in the embryo 

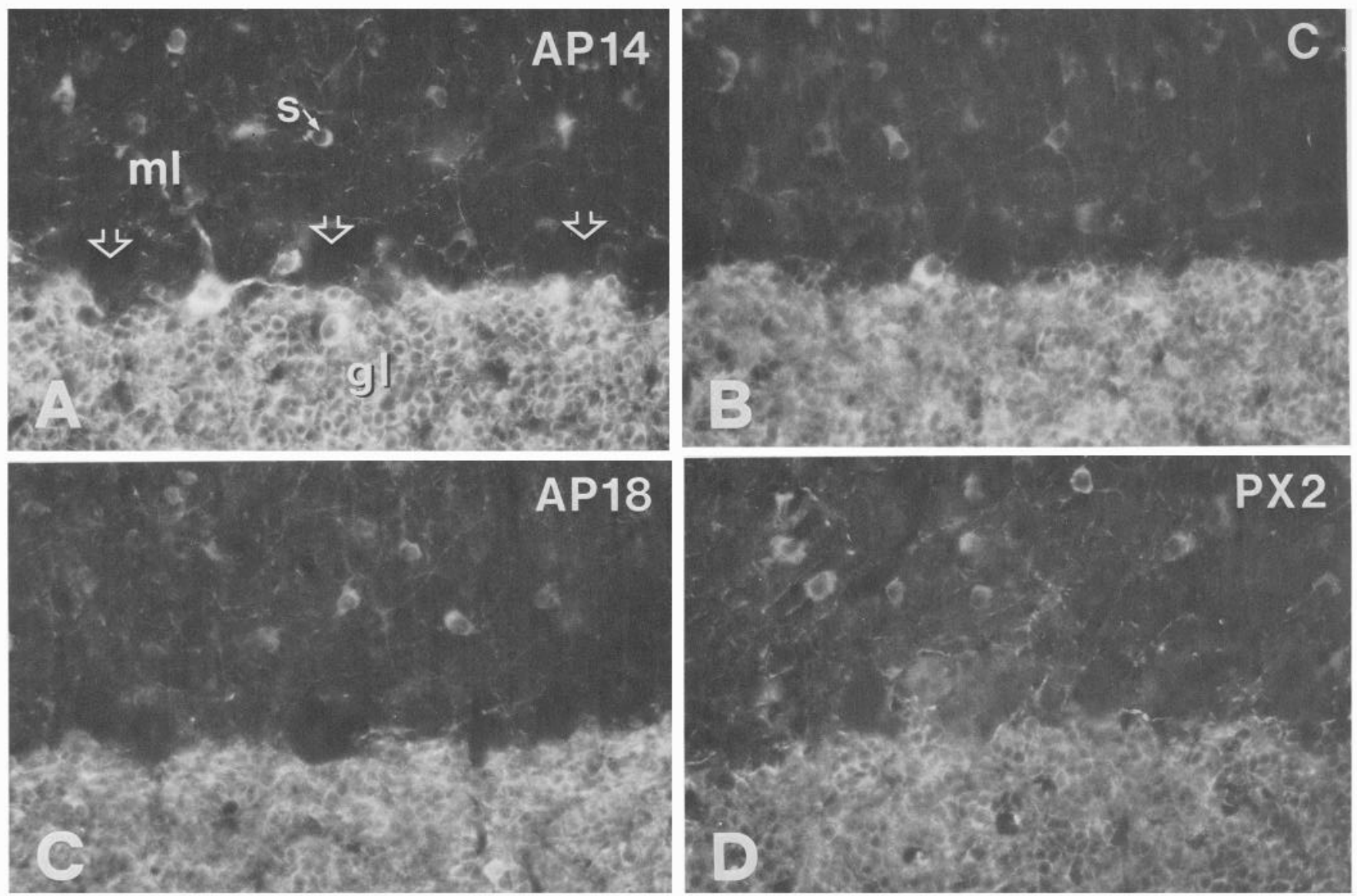

Figure 7. Adjacent sections of a P9 quail cerebellum stained with 3 monoclonal antibodies to MAP2 (AP14, C, and AP18) and polyclonal antiMAP2 sera (PX2). The granule cell layer $(g l)$ and stellate cells $(s)$ within the molecular layer $(m l)$ are stained with each of the monoclonal antibodies and polyclonal antisera, but Purkinje cells (open arrows) and their dendrites are unstained.

than in the adult but also appears in developing neurons (granule cells and stellate cells) before the HMW form of MAP2.

\section{HMW MAP2 and dendrogenesis}

In the adult mammalian CNS, the HMW form of MAP2 is more abundant in dendrites than in axons (Matus et al., 1981; Vallee, 1982; Bernhardt and Matus, 1984; Caceres et al., 1984; DeCamilli et al., 1984; Huber and Matus, 1984b). We have recently shown that the appearance of HMW MAP2 succeeds axonogenesis and, instead, is correlated with the onset of dendrite formation. Retinal ganglion cells and spinal motor neurons do not stain with AP14 until well after the onset of axon formation by these cells but comparable to the timing of dendrite formation (Tucker et al., 1988a, b). In the current study we show that cerebellar granule cells do not stain with AP14 until they have reached their final location in the granular layer, where they generate their dendritic tree. Thus, the microdifferentiation of the neuron is accompanied from the onset by the compartmentalization of HMW MAP2, suggesting a fundamental role for this protein in the formation of dendrites (see also Bernhardt and Matus, 1982; Bernhardt et al., 1985).

\section{MAP2 is not found in mature quail Purkinje cell dendrites}

MAP2 is not detectable in the Purkinje cells of the mature quail cerebellum, in spite of the abundance of HMW MAP2 in these cells in the embryo. Since the first descriptions of its compartmentalization in dendrites (Matus et al., 1981; Bernhardt and Matus, 1984), MAP2 has been believed to be involved in the maintenance of dendritic form or some other function fundamental to this class of neuronal process. The absence of MAP2 staining in quail Purkinje cell dendrites with several monoclonal antibodies directed against different MAP2 epitopes, as well as a species cross-reactive polyclonal antiserum, is thus an unexpected and significant result. The fact that we obtained the same result with each of these antibodies excludes the possibility that the absence of MAP2 staining is the result of masking of the MAP2 epitope or limited antibody cross-reactivity. It is also important to note that all of the MAP2 antibodies tested here stained the cell bodies and dendrites of other neurons within the quail cerebellar cortex. Except for the absence of staining within Purkinje cells, the staining patterns with these antibodies in the quail are identical to the staining patterns seen in the rat cerebellum. In addition, it is clear that the Purkinje cells and their dendrites are intact in our sections. They can be stained with $\beta$-tubulin antibodies and are visible in negative relief when sections are stained with antibodies to an axon-specific epitope of tau (results not shown). It remains possible that MAP2 is present in Purkinje cells but at trace levels. Nevertheless, the presence of HMW MAP2 staining in developing quail Purkinje cells and its subsequent disappearance in the P9 cerebellum 
E 10

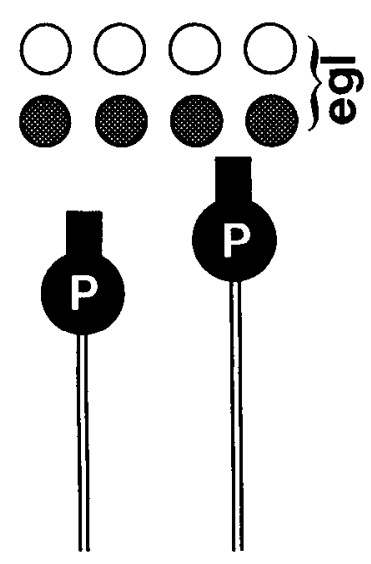

E14

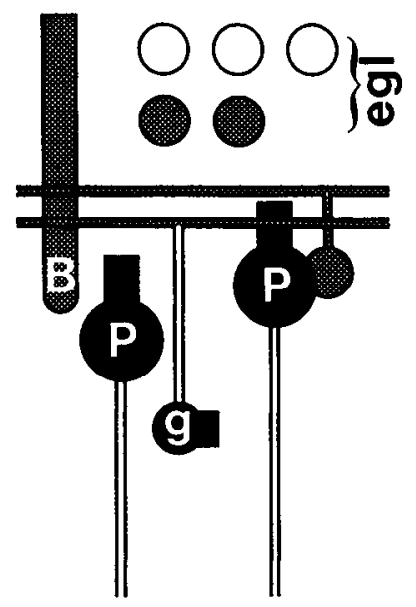

P9

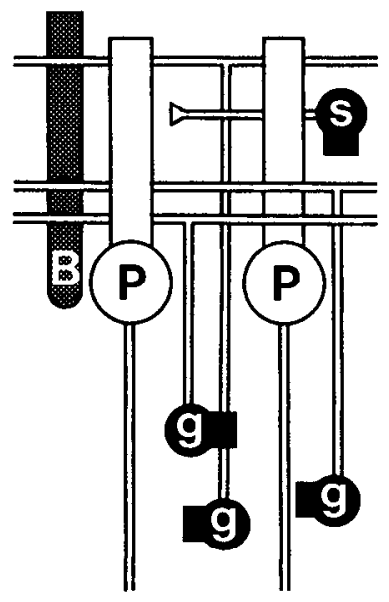

Figure 8. A highly schematic representation of the ontogeny of MAP2 forms in the developing avian cerebellum. High-molecular-weight (HMW) MAP2 is represented by solid black, whereas low-molecular-weight (LMW) MAP2 is indicated by stippling. In the embryonic cerebellum (E10, E14), HMW MAP2 is found only in cells that have commenced dendrite formation $(P$, Purkinje cell; $g$, granule cell), whereas LMW MAP2 is found in differentiating neurons in the external granular layer $(e g l)$ and the Bergmann fibers $(B)$ of Golgi epithelial cells. In the mature cerebellum (P9), HMW MAP2 is no longer detectable in Purkinje cell dendrites, and LMW MAP2 persists in Bergmann fibers ( $s$, stellate cell). suggests that HMW MAP2 is associated with the establishment of these dendrites and not with their function or with maintenance of their morphology in the mature Purkinje cell.

In a previous study (Huber and Matus, 1984a), MAP2 staining of adult rat Purkinje cell dendrites was shown to diminish more rapidly than the staining of granule cell dendrites with increasing dilutions of $\mathrm{MAb} / \mathrm{C}$. In contrast, the staining with diluted antibody against another major, HMW MAP, MAP1 [the same protein as MAP1A (Bloom et al., 1984)] persisted in Purkinje cell dendrites, implying that MAP1 was the predominant MAP in these processes. Although MAP2 may be present in relatively low amounts in adult rat Purkinje cell dendrites, nevertheless it is associated with $R_{\mathrm{II}}$, which is absent together with MAP2 from mature quail Purkinje cell dendrites. This suggests that cAMP-dependent protein kinase activity is intimately associated with MAP2 function in mature mammalian Purkinje cells.

\section{LMW MAP2 and neurite microdifferentiation}

In contrast to the dendritic compartmentalization of HMW MAP2, LMW MAP2 is found in embryonic axons. LMW MAP2 is present in the white matter of the embryonic quail spinal cord before the appearance of oligodendroglia (Tucker et al., 1988b), and it is also present in ganglion cell axons in the developing retina (Tucker et al., 1988a). In the mature avian cerebellum, LMW MAP2 may be present in parallel fibers in the molecular layer, though the precise nature of the faint staining of the mature molecular layer as well as staining in the molecular layer in the E14 embryo could not be determined with our frozen sections.

Unlike HMW MAP2, which is found only in neurons in the quail embryo, LMW MAP2 is found in certain supporting cells as well: for example, in the avian cerebellum, LMW MAP2 is seen in the Bergmann fibers. This is related to the observation that LMW MAP2 is an abundant MAP in the C6 glioma cell line (Garner et al., 1988; Garner and Matus, 1988). LMW MAP2 may be the form of MAP2 that has been described by others in glia (Papasozomenos and Binder, 1986) and other non-neuronal cells (e.g., see Wiche et al., 1984).

If LMW MAP2 shares a common tubulin binding domain with HMW MAP2, a possible function of LMW MAP2 may be to compete with HMW MAP2 for tubulin binding sites, effec- tively reducing the amount of the latter protein binding to the microtubule lattice. Thus, the presence of LMW MAP2 in embryonic axons may effectively inhibit the binding of HMW MAP2 in these processes, contributing to the dendritic distribution of the larger protein. The timing of LMW MAP2 expression also suggests that this protein could be involved in activities associated with cell migration, e.g., granule cell migration from the external granular layer. Further in vitro and in situ experiments are needed to test these suppositions.

Quail LMW MAP2 can be phosphorylated in situ, as is demonstrated by the change in its electrophoretic mobility following treatment with alkaline phosphatase. This is in agreement with the results of Garner et al. (1988), who observed that rat MAP2c fragments generated by limited proteolytic digestion during the course of peptide mapping could be more clearly resolved following phosphatase treatment. Since the phosphorylation state of HMW MAP2 affects the ability of this protein to assemble tubulin into microtubules (Jameson and Caplow, 1981; Burns et al., 1984) and to bind to microtubules in vitro (Murthy and Flavin, 1983), it would bc interesting to determine if the binding properties of LMW MAP2 are also affected by phosphorylation. The number of LMW MAP2 bands generated by phosphorylation appears to decrease during development (Fig. $2 A$ ), but it is unknown if this is due to changes in the compartmentalization of this protein (e.g., its appearance in glia or disappearance from axons) or if it represents a more general change related to developmental age.

In conclusion, we have shown that the forms, cellular localization, and developmental regulation of MAP2 are conserved in the rat and quail, implying a fundamental role for these proteins in cerebellum morphogenesis. LMW MAP2 appears in differentiating neurons before HMW MAP2; the precocious and widespread appearance of LMW MAP2 may contribute to the compartmentalization of HMW MAP2. Finally, MAP2 is abundant only transiently in the dendrites of Purkinje cells in the quail, suggesting the MAP2 may regulate the establishment of these processes but not the maintenance of their characteristic form.

\section{References}

Bernhardt, R., and A. Matus (1982) Initial phase of dendrite growth: Evidence for the involvement of high molecular weight microtubule- 
associated proteins (HMWP) before the appearance of tubulin. J. Cell Biol. 92: 589-593.

Bernhardt, R., and A. Matus (1984) Light and electron microscopic studies of the distribution of microtubule-associated protein 2 in rat brain: A difference between dendritic and axonal cytoskeletons. $J$. Comp. Neurol. 226: 203-221.

Bernhardt, R., G. Huber, and A. Matus (1985) Differences in the developmental patterns of three microtubule-associated proteins in the rat cerebellum. J. Neurosci. 5: 977-991.

Binder, L. I., A. Frankfurter, H. Kim, A. Caceres, M. R. Payne, and L. I. Rebhun (1984) Heterogeneity of microtubule-associated protein 2 during rat brain development. Proc. Natl. Acad. Sci. USA 81: 5613 5617.

Binder, L. I., A. Frankfurter, and L. I. Rebhun (1986) Differential localization of MAP2 and tau in mammalian neurons in situ. Ann. NY Acad. Sci. 466: 145-166.

Bloom, G. S., T. A. Schoenfeld, and R. B. Vallee (1984) Widespread distribution of the major polypeptide component of MAP1 (microtubule-associated protein 1) in the nervous system. J. Cell Biol. 98 . 320-330.

Burgoyne, R. D., and R. Cumming (1984) Ontogeny of microtubuleassociated protein 2 in rat cerebellum: Differential expression of the doublet polypeptides. Neuroscience 11: 157-167.

Burns, R. G., K. Islam, and R. Chapman (1984) The multiple phosphorylation of the microtubule-associated protein MAP2 controls the MAP2 tubulin interaction. Eur. J. Biochem. 141: 609-615.

Caceres, A., L. I. Binder, M. R. Payne, P. Bender, L. Rebhun, and O. Steward (1984) Differential subcellular localization of tubulin and the microtubule-associated protein MAP2 in brain tissue as revealed by immunocytochemistry with monoclonal hybridoma antibodies. $\mathbf{J}$. Neurosci. 4: 394-410.

DeCamilli, P., P. E. Miller, F. Navone, W. E. Theurkauf, and R. B. Vallee (1984) Distribution of microtubule-associated prótein 2 in the nervous system of the rat studied by immunofluorescence. Neuroscience 11:817-846.

DeCamilli, P., M. Moretti, S. D. Donini, U. Walter, and S. M. Lohmann (1986) Heterogeneous distribution of the cAMP receptor protein RII in the nervous system: Evidence for its intracellular accumulation on microtubules, microtubule-organizing centers, and in the area of the Golgi complex. J. Cell Biol. 103: 189-203.

Garner, C. C., and A. Matus (1988) Different forms of microtubuleassociated protein 2 are encoded by separate mRNA transcripts. J. Cell Biol. 106: 779-783.

Garner, C. C., B. Brugg, and A. Matus (1988) A 70 kDa microtubuleassociated protein (MAP2c), related to MAP2. J. Neurochem. 50: 609-615.

Hemmings, B. A., M. Schwarz, S. R. Adavani, and D. A. Jans (1986) Expression cloning of a cDNA encoding the type II regulatory subunit of the cAMP-dependent protein kinase. FEBS Lett. 209: 219-222.

Herzog, W., and K. Weber (1978) Fractionation of brain microtubuleassociated proteins. Isolation of two different proteins which stimulate tubulin polymerization in vitro. Eur. J. Biochem. 92: 1-8.

Huber, G., and A. Matus (1984a) Immunocytochemical localization of microtubule-associated protein 1 in rat cerebellum using monoclonal antibodies. J. Cell Biol. 98: 777-781.

Huber, G., and A. Matus (1984b) Differences in the cellular distributions of two microtubule-associated proteins, MAP1 and MAP2, in the rat brain. J. Neurosci. 4: 151-160.

Jameson, L., and M. Caplow (1981) Modification of microtubule steadystate dynamics by phosphorylation of the microtubule-associated proteins. Proc. Natl. Acad. Sci. USA 78: 3413-3417.

Karr, T. L., H. D. White, and D. L. Purich (1979) Characterization of brain microtubule proteins prepared by selective removal of mitochondrial and synaptosomal components. J. Biol. Chem. 254: 61076111.
Laemmli, U. K. (1970) Cleavage of structural proteins during the assembly of the head of the bacteriophage T4. Nature 227:680-685.

Lohmann, S. M., P. DeCamilli, I. Einig, and U. Walter (1984) High affinity binding of the regulatory subunit (RII) of cAMP-dependent protein kinase to microtubule-associated and other cellular proteins. Proc. Natl. Acad. Sci. USA 81: 6723-6727.

Matus, A. (1988) Microtubule-associated proteins: Their potential role in determining neuronal morphology. Annu. Rev. Neurosci. 11:2944.

Matus, A., R. Bernhardt, and T. Hugh-Jones (1981) High-molecular weight microtubule-associated proteins are preferentially associated with dendritic microtubules in the brain. Proc. Natl. Acad. Sci. USA 78: 3010-3014.

Murphy, D. B., and G. G. Borisy (1975) Association of high molecular weight proteins with microtubules and their role in microtubule assembly in vitro. Proc. Natl. Acad. Sci. USA 72: 2696-2700.

Murthy, A. S., and M. Flavin (1983) Microtubule assembly using the microtubule-associated protein MAP2 prepared in defined states of phosphorylation with protein kinase and phosphatase. Eur. J. Biochem. 137: 37-46.

Nunez, J. (1986) Differential expression of microtubule components during brain development. Dev. Neurosci. 8: 125-141.

Olmsted, J. B. (1986) Microtubule-associated proteins. Annu. Rev. Cell Biol. 2: $421-457$.

Papasozomenos, S. C., and L. I. Binder (1986) Microtubule-associated protein 2 (MAP2) is present in astrocytes of the optic nerve but absent from astrocytes of the optic tract. J. Neurosci. 6: 1748-1756.

Papasozomenos, S. C., and L. I. Binder (1987) Phosphorylation determines two distinct species of tau in the central nervous system. Cell Motil. Cytoskel. 8: 210-226.

Ramón y Cajal, S. (1929) Études sur la Neurogenèse de quelques Vertébrés, L. Guth, Trans., Charles C Thomas, Springfield, IL.

Riederer, B., and A. Matus (1985) Differential expression of distinct microtubule-associated proteins during brain development. Proc. Natl. Acad. Sci. USA 82: 6006-6009.

Sloboda, R. D., W. L. Dentler, and J. L. Rosenbaum (1976) Microtubule-associated proteins and the stimulation of tubulin assembly in vitro. Biochemistry $15: 4497-4505$.

Sternberger, L. A., and N. H. Sternberger (1983) Monoclonal antibodies distinguish phosphorylated and nonphosphorylated forms of neurofilaments in situ. Proc. Natl. Acad. Sci. USA 80: 6126-6130.

Theurkauf, W. E., and R. B. Vallee (1982) Molecular characterization of the cAMP-dependent protein kinase bound to microtubule-associated protein 2. J. Biol. Chem. 258: 7883-7886.

Towbin, H., T. Stehelin, and J. Gordon (1979) Electrophoretic transfer of protein from polyacrylamide gels to nitrocellulose sheets: Procedure and some application. Proc. Natl. Acad. Sci. USA 76: 4354-4356.

Tucker, R. P., L. I. Binder, and A. I. Matus (1988a) Differential localization of developmentally-regulated MAP2 isoforms in the retina. Dev. Brain Res. 38: 313-318.

Tucker, R. P., L. I. Binder, and A. I. Matus (1988b) Neuronal microtubule-associated proteins in the embryonic avian spinal cord. $J$. Comp. Neurol. 271: 44-55.

Vallee, R. (1982) A taxol-dependent procedure for the isolation of microtubules and microtubule-associated proteins (MAPs). J. Cell Biol. 92: 435-442.

Vallee, R. B., M. J. DiBartolomeis, and W. E. Theurkaur (1981) A protein kinase bound to the projection portion of MAP2 (microtubule-associated protein 2). J. Cell Biol. 90: 568-576.

Wiche, G., E. Briones, C. Koszka, U. Artlieb, and R. Krepler (1984) Widespread occurrence of polypeptides related to neurotubule-associated proteins (MAP1 and MAP2) in nonneuronal cells and tissues. EMBO J. 3: 991-998. 